\title{
The Smart Grid Technology Development Strategy of Taiwan
}

\author{
Faa-Jeng Lin1, Yenhaw Chen'2, Su-Ying Lu², Yvonne Hsu² \\ ${ }^{1}$ Department of Electrical Engineering, National Central University, Taiwan \\ ${ }^{2}$ Research Division 1, Taiwan Institute of Economic Research, Taiwan \\ Email: linfj@ee.ncu.edu.tw, yenhaw@gmail.com
}

Received 11 April 2016; accepted 16 May 2016; published 19 May 2016

Copyright (C) 2016 by authors and Scientific Research Publishing Inc.

This work is licensed under the Creative Commons Attribution International License (CC BY).

http://creativecommons.org/licenses/by/4.0/

c) (i) Open Access

\begin{abstract}
In Taiwan, in corresponding to the policy of reducing $\mathrm{CO}_{2}$ emission, reforming current energy structure, and saving energy, the National Energy Program (NEP)-Smart Grid General Project Phase 1 was implemented. The objectives of this project are meant to enhance the robustness of the power grid, reduce greenhouse gas emission, increase the penetration rate of renewable energy and develop smart grid industry in Taiwan. This study will introduce the positioning of the Smart Grid General Project among overall smart grid development, the results of Phase 1, the smart grid technology commercialization process of Phase 2, and the promotion model with collaboration between industry, universities and research units.
\end{abstract}

\section{Keywords}

Grid, National Energy Program, Demonstration Site, Technology Commercialization, Taiwan

\section{Introduction}

Smart grid technology uses information, communication, and automation technology to deploy an integrated power grid with smart power generation, transmission, distribution and users. Smart grid emphasizes automation, safety, and the close cooperation between the users and suppliers to improve the operating efficiency of power system, to enhance power quality and to solidify grid reliability. The use of smart grid technology is also aligned with the policy goals of expanding the application of renewable energy, energy conservation, and carbon reduction. In 2012, the Executive Yuan of Taiwan approved the inclusion of "Smart Grid Master Plan" as a benchmark project in the "Master Plan of Energy Conservation and Carbon Reduction”. The Ministry of Economic Affairs (MOEA), the National Science Council (NSC), the Atomic Energy Council (AEC), the National Development Council (NDC), the Board of Science and Technology (BOST), the Department of Economics, Energy and Agriculture (DEEA), the Taiwan Power Company (Taipower) and the subordinate agencies of the MOEA 
subsequently established "Smart Grid Task Force” to promote the development of smart grid technology. The Bureau of Energy, MOEA, is responsible for the "Smart Grid Master Plan".

The mission-oriented smart grid research program, NEP-Smart Grid General Project has started in 2010 [1]. Professor Faa-Jeng Lin has been assigned to be the principle investigator (PI) by NSC, which has been renamed as the Ministry of Science and Technology (MOST) since 2014. The responsibilities of the project include the planning and execution of system and technology development, pilot trials, promotion and implementation, administrative research, and the system testing platform [2]. The purpose of the Smart Grid General Project is to establish an overall development strategy to face the challenges of the aforementioned power system and industry. Concrete, effective action plans to realize the vision of "enhancing energy security, improving carbon emissions, and creating an energy industry" have been proposed along with the development of Taiwan's power equipment industry. These efforts have assisted the development of a high quality, high efficiency, user-oriented, and environmentally friendly power grid. The Smart Grid General Project Phase 1 was implemented from 2010 to 2013. Phase 2 was launched in 2014 and slated to continue for five years, receiving approximately NTD \$350 million in R\&D funding annually [3]. This study will introduce the positioning of the Smart Grid General Project among overall smart grid development, the results of Phase 1, and the smart grid technology commercialization process of Phase 2 .

\section{Overall Planning of Smart Grid in Taiwan}

\subsection{Challenges of Taiwan's Power System}

Taiwan's power system is a large, centralized system with its main sources of power comprising thermal (e.g. oil, coal and gas combustion) and nuclear (accounting for $94 \%$ of total generating capacity), and a few hydro and renewable energy sources (accounting for $4.5 \%$ of total generating capacity) [4]. The system is characterized by large generator units and concentrated loading. Due to the long distances between the power plants and the users, all electricity generated by the nuclear, thermal or hydro power plants must be converted to high voltage through the transmission and transformer system, and subsequently transmitted over power lines and passed through substations before being supplied to users, resulting in certain amounts of energy loss (between 2009 2013, line loss was approximately 4.59\%) [5]. While urban and industrial areas experience concentrated loads and rapidly increasing demand, the siting and construction of substations is difficult and often faces local protests. The inability of centralized power supplies to transmit electricity according to demand results in regional power bottlenecks. In addition, long power transmission distances and the inter-connection of large grids make it difficult to track rapid changes in loading. Failures can be easily propagated through the grid leading to the paralysis of the power system. The massive grid and overly-concentrated power plants are also vulnerable to attack, putting national security at risk. The power supply is now "sufficient but unevenly distributed". Due to national security and energy security considerations, the introduction of the smart grid to increase distributed energy resources (DER) and grid efficiency is now the established policy and direction of development in Taiwan [6].

\subsection{Smart Grid Master Plan}

The "Smart Grid Master Plan” was approved by the Executive Yuan in August, 2012. The vision called for the establishment of a high quality, high efficiency, and environmentally friendly smart grid, promoting a low-carbon society and sustainable development. The construction of smart grid in Taiwan seeks to accomplish the four following goals: guarantee a stable power supply, promote energy conservation and carbon reduction, increase green energy usage, and guidance of the low-carbon industry. The objectives are shown in Table 1. The "Smart Grid Master Plan" promotion strategy is divided into six dimensions: "Smart Power Generation and Dispatching”, "Smart Power Transmission”, “Smart Power Distribution”, “Smart User”, “Smart Grid Industry Development”, and "Smart Grid Infrastructure”. The Smart Grid General Project is mainly responsible for standards and $\mathrm{R} \& \mathrm{D}$ aspects under the "Establishment of Environment" dimension. The project seeks to complete the short and medium-term technology R\&D items in the Smart Grid Master Plan as shown in Figure 1 [7].

\section{Smart Grid General Project Phase 1}

\subsection{Phase 1 Execution}

As shown in Figure 2, Smart Grid General Project Phase 1 has been divided into two aspects: technology 
Table 1. Objectives of smart grid master plan.

\begin{tabular}{|c|c|c|c|c|}
\hline Benefit & Objective & 2010 & 2020 & 2030 \\
\hline $\begin{array}{l}\text { Security \& Reliability } \\
\text { in Power Grid }\end{array}$ & $\begin{array}{l}\text { System Average } \\
\text { Interruption Duration } \\
\text { Index (SAIDI) }\end{array}$ & $\begin{array}{c}\text { System Average } \\
\text { Interruption Duration } \\
\text { Index (SAIDI) }\end{array}$ & 16 mins/customer $\cdot$ year & 15.5 mins/customer year \\
\hline Energy Efficiency & $\begin{array}{l}\text { Efficiency in } \\
\text { Thermal Plants }\end{array}$ & $\begin{array}{c}\text { Efficiency in } \\
\text { Thermal Plants }\end{array}$ & $44.73 \%$ & $(2023,44.95 \%)$ \\
\hline Renewable & $\begin{array}{c}\text { Percentage of Installed } \\
\text { Capacities }\end{array}$ & $\begin{array}{c}\text { Percentage of Installed } \\
\text { Capacities }\end{array}$ & $20 \%$ & $30 \%$ \\
\hline Carbon Reduction & $\begin{array}{l}\text { Carbon Oxide } \\
\text { Reduction }\end{array}$ & $\begin{array}{l}\text { Carbon Oxide } \\
\text { Reduction }\end{array}$ & 35.99 million tons & 114.71 million tons \\
\hline
\end{tabular}

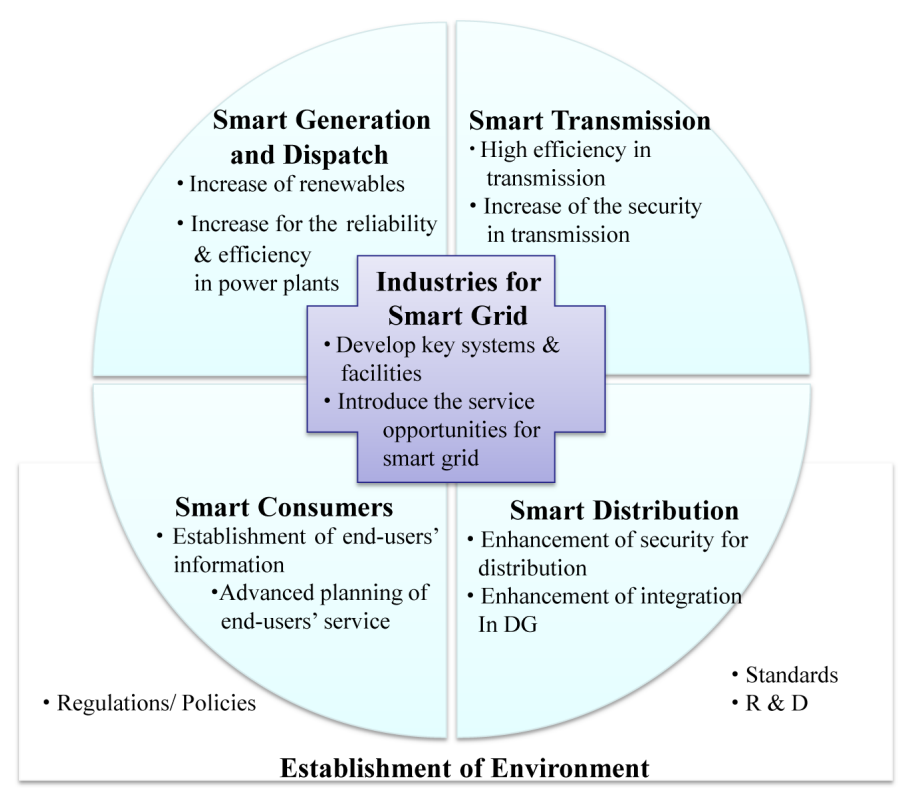

Figure 1. Smart grid master plan in Taiwan.

development and application. Research in the technology development aspect covers: 1) Power Quality; 2) Transmission/Distribution Control; 3) Distribution Automation; 4) Micro Grid Control; 5) Smart Meter (AMI) and Energy Information and Communication Technology (EICT); 6) Energy Management and Demand Response (DR) Technology; 7) Power Electronics; and 8) Standards. The application aspect covers: 1) Micro Grid; 2) AMI; 3) Smart Home (Building) Energy Management; 4) Advanced Distribution Automation; 5) Advanced Application of Wide Area Measurement System; 6) Transmission System Power Quality Monitoring Technology Development and Advanced Application; and 7) Electric Vehicle Charging Management Strategy. The planning was proposed for seven pioneering pilot projects. The technology development aspect is composed of government related technology projects with the research results used to support the pioneering pilot projects of the application aspect.

\subsection{Collaboration Promotion Model}

To ensure proper communication between the Smart Grid General Project and the industry, and encourage industry participation during its execution, the Smart Grid General Project established the "Taiwan Smart Grid Industry Association" (TSGIA) with the help of the Taiwan Institute of Economic Research (TIER). TSGIA is organized as shown in Figure 3. Apart from assembling the resources of Taiwan's heavy electrical industry and smart grid-related industries for the joint development of smart grid technologies, support was also channeled 


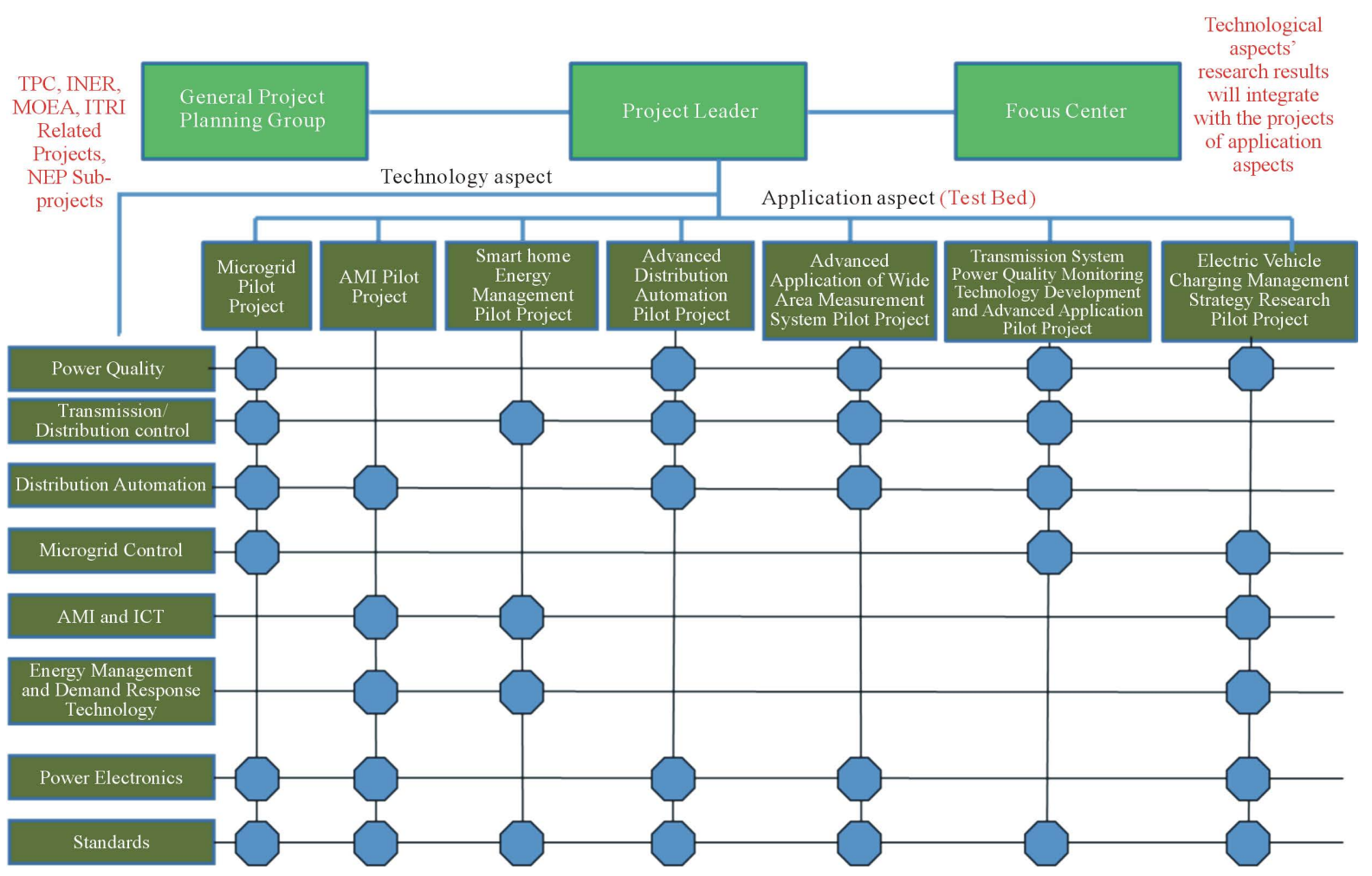

Figure 2. Smart grid general project organization structure.

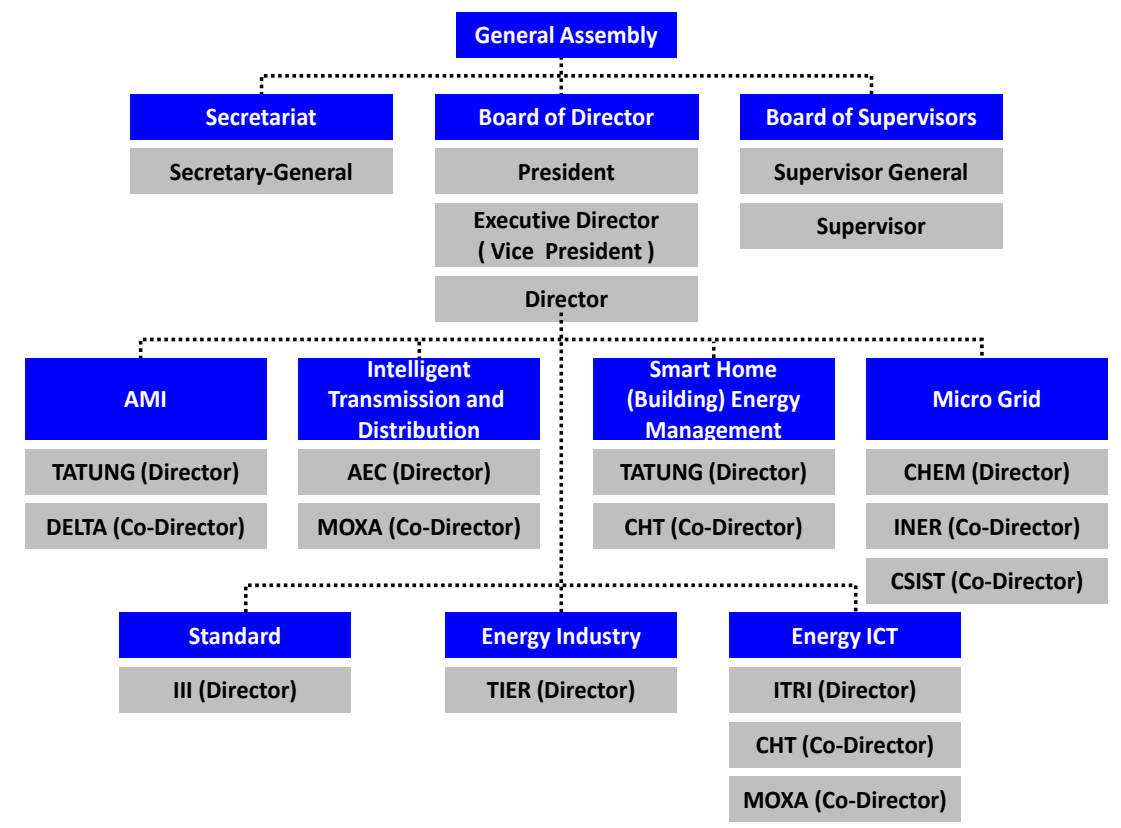

Figure 3. Organization of TSGIA.

towards the defining of smart grid standard and international cooperation. TSGIA currently has 43 group members including Taipower, the Taiwan Stock Exchange/The Gre Tai Securities Market-listed companies, the Institute for Information Industry (III), ITRI, the Taiwan Power Research Institute (TPRI), INER, the National Chung-Shan Institute of Science \& Technology (CSIST), TIER, Taiwan Electric Research \& Testing Center (TERTEC), the Electronics Testing Center of Taiwan (ETC) and other research or certification entities. Individ- 
ual members include 53 experts and academics involved with Smart Grid General Project [8].

\subsection{Phase 1 Results}

Under Smart Grid General Project Phase 1 and the development of EICT by the MOEA, 18 smart grid demonstration sites have so far been established with the guidance of the MOST, Bureau of Energy, MOEA, and private companies. The demonstration sites are listed in Table 2 and can be divided into two main categories, "Smart User Energy Management System (EMS)" and "Smart Distribution System and Virtual Power Plant (VPP) Technologies". The experiences and results from the development of these demonstration sites will help the commercialization of smart grid technology, integrated testing and system verification, laying the key foundations for the full-scale deployment and industry promotion of smart grid [9].

In smart grid development, according to TSGIA's statistics, during the Smart Grid General Project period, sales of smart grid products grew from NTD\$2.11 billion in 2009 to NTD\$12.42 billion in 2012 as shown in Figure 4. Total sales of smart grid-related products are therefore growing at an average rate of $80.62 \%$ each year. Sales in the domestic market have continued to grow steadily from 2009-2012. In the overseas market, weaker than expected global economic development led to a slower growth in the export sales in 2011, but the industry is still growing overall [10].

Table 2. Summary of smart grid demonstration sites in Taiwan.

\begin{tabular}{|c|c|c|}
\hline Type & Name of the Demonstration Site & Location \\
\hline \multirow{11}{*}{ Smart User EMS } & AMI Reading \&DR System & National Central University in Taoyuan \\
\hline & Demonstration of AMI Reading in a Metropolitan Setting & Minsheng Community in Taipei \\
\hline & AMI System and Home EMS Demonstration Area & Renjian Qingjing Community in Tainan \\
\hline & Smart Grid Control Center and Smart Home Demo Room & Tatung University in Taipei \\
\hline & Smart Home (Building) EMS & $\begin{array}{l}\text { Chi Mei Building, National Cheng Kung } \\
\text { Universityin Tainan }\end{array}$ \\
\hline & Smart Building Energy Conservation Demonstration Area & Zhongxing Campus, ITRI in Hsinchu \\
\hline & Hypermarket Energy Conservation Management System & RT-Mart's Toufen Store in Miaoli \\
\hline & Convenience Store Energy Conservation Management System & Family Mart throughout Taiwan \\
\hline & $\begin{array}{c}\text { Wastewater Treatment Plant Power Equipment Monitoring } \\
\text { and Energy Conservation Management System }\end{array}$ & $\begin{array}{l}\text { Hsinchu Science Park Wastewater } \\
\text { Treatment Plant }\end{array}$ \\
\hline & $\begin{array}{l}\text { Optimizing Control System for a High-tech } \\
\text { Plant Ice Water System }\end{array}$ & Central Taiwan Science Park in Taichung \\
\hline & Furnace Optimized Operation Demonstration System & $\begin{array}{l}\text { Toufen Plant, China Petrochemical } \\
\text { Development Corp. in Miaoli }\end{array}$ \\
\hline \multirow{7}{*}{$\begin{array}{c}\text { Smart Distribution } \\
\text { System and VPP } \\
\text { Technologies }\end{array}$} & Advanced Distribution Automation Demo System & Taipower Shulin TPRI Lab in Taipei \\
\hline & 100 kW Autonomous Micro Grid Demonstration System & $\begin{array}{l}\text { INER, Atomic Energy Council, } \\
\text { Executive Yuan in Taoyuan }\end{array}$ \\
\hline & Smart DC Power System Educational Demonstration House & National Chung Cheng University in Chiayi \\
\hline & Smart AC/DC Hybrid Micro Grid Demonstration System & $\begin{array}{l}\text { Chung-Hsin Electric and Machinery } \\
\text { Manufacturing Corp. in Taoyuan }\end{array}$ \\
\hline & Micro Grid and Electric Vehicle Demonstration Site & Yulon Group Building in Taipei \\
\hline & Dongkeng Smart Grid Demonstration Project & Dongkeng Community in Kinmen \\
\hline & Penghu Smart Grid Demonstration Site & Penghu Archipelago \\
\hline
\end{tabular}




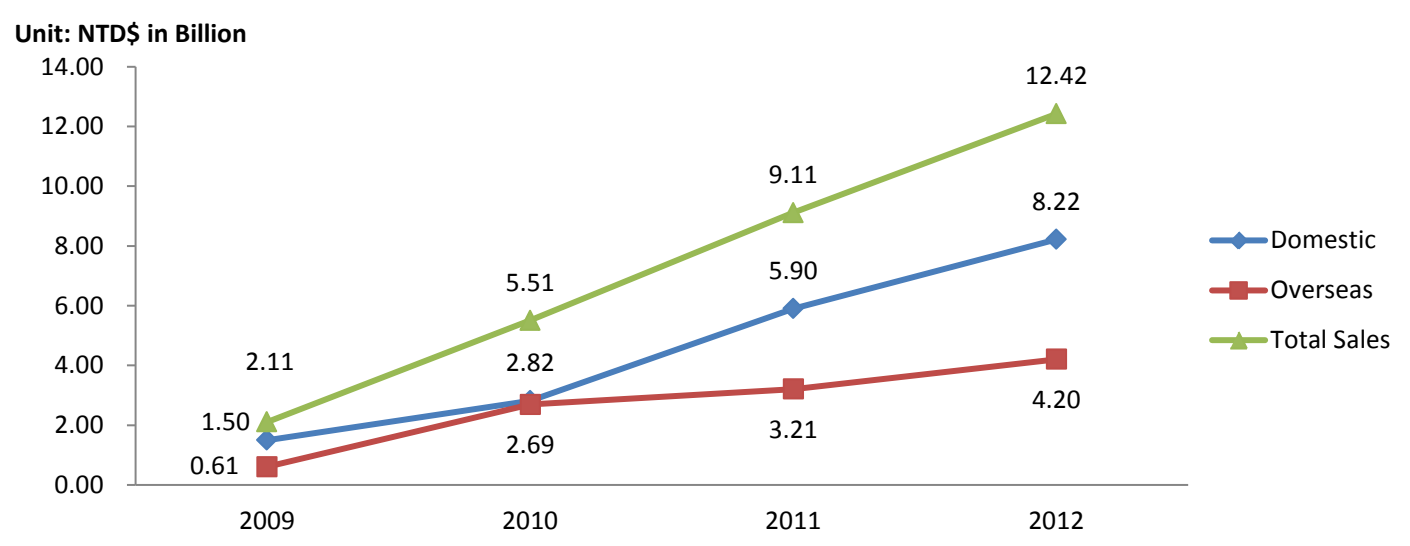

Figure 4. Total sales of the Taiwan smart grid industry, 2009-2012.

\section{Smart Grid General Project Phase 2}

\subsection{NEP Phase 2-VPP Architecture}

It has become increasingly difficult in recent years to add more nuclear, thermal and large wind farms in Taiwan. Adding or upgrading transmission/distribution lines and substations have become difficult as well. However, power consumption has continued to grow each year, so the power supply and dispatch flexibility has come under pressure. The economic loss of unreliable power is hard to estimate. In terms of loading, the reduction in proportion of power used by presumer users and the increase in power consumption by consumer users has changed the power usage structure. The areas experiencing power supply congestion are mostly in densely populated urban regions. At the same time, government incentives for small-scale renewable energy have led to an increase in grid-connected distributed solar and wind generation. However, the lack of a dispatch mechanism affected the power supply quality of the grid [11]. The strategy adopted by the NEP Phase 2 in response was to develop the VPP solution. The Energy Conservation General Project, Alternative Energy General Project, and Smart Grid General Project were designated as components of the VPP architecture [3]. EICT will be used as the basis for constructing a VPP solution made up of four components: Smart transmission and distribution network, Demand-side distributed EMS, Automatic DR system, and Demand-side market. Demand-side management (DSM) would be integrated with the industries of solar power, wind power, energy storage and fuel cell equipment for transforming into power supply service systems with high added value.

\subsection{NEP Phase 2-Smart Grid Technology Commercialization Process}

Smart Grid General Project Phase 2 is organized into five tracks, which are smart user EMS technology development, advanced smart distribution system technology development, smart transmission system technology development, smart grid standards and industry promotion, and smart grid demonstration system deployment. All of the projects are mission-oriented application projects with early industry participation. Smart Grid Technology Commercialization Process of Phase 2 goes through these four stages: 1) Equipment and System Development; 2) Technology Commercialization; 3) Demonstration; and 4) Implementation. In addition to continue developing new equipment and system technologies that encompass user, distribution and transmission, the validation of technologies developed in Phase 1 will also be implemented. Moreover, the "Penghu Smart Grid Demonstration Project" and the "Integrated Application Project for Demand Response, Distributed Generation and Energy Storage" in stage 3 are used as platform for coordination with Taipower's smart grid-related technology requirements and deployment schedule. The technology commercialization process of Smart Grid General Project Phase 2 will be implemented as shown in Figure 5 [12].

\subsection{Penghu Smart Grid Demonstration Project}

In 2010, Executive Yuan approved "The Penghu Low-carbon Island Plan" and was promoted by the Bureau of Energy, MOEA. The Penghu Low-carbon Island Planaims to complete a low-carbon green living area demonstration based on the vision and goals of the Penghu Low-carbon Island. Low-carbon lifestyle services along 
with energy-saving/carbon-reduction technology will be applied and integrated with tourism services to expand the application of green energy products, accelerating Taiwan to join the ranks of low-carbon nations [13]. According to the Smart Grid Master Plan, Penghu Smart Grid Demonstration Project will cooperate with The Penghu Low-carbon Island Plan to bring the smart grid-related technologies and industries together to establish an integrated, centralized demonstration site in Penghu archipelago as shown in Figure 6 to provide Taiwanese industry with an opportunity for technical trials. The proposal will validate smart grid performance and provide a basis for industry development. The Penghu Smart Grid Demonstration Project will plan out the details of the demonstration site based on the Bureau of Energy, MOEA's detailed planning for the Penghu Low-Carbon Island Plan, and is being planned and deployed in two stages. Phase 1 of deployment will run for three years from 2013 to 2015. Phase 2 of deployment will also run for three years from 2016 to 2018.

In the future, Penghu's low-carbon power will be supplied through undersea cable and DERs. For the cumulative risks from interruption of power supply and transmission, distributed generation will serve to stabilize the power supply. The grid islanding mechanism will also need to be established to maintain the continuity of power system during a large-scale power outage in the transmission and distribution grid (including undersea cable). Regional backup power supplies can then be preserved to supply the emergency backup power needed for information and communications equipment, medical facilities, and transportation infrastructure. Building a smart grid demonstration site in Penghu archipelago will enable Micro Grid and advanced distribution line automation

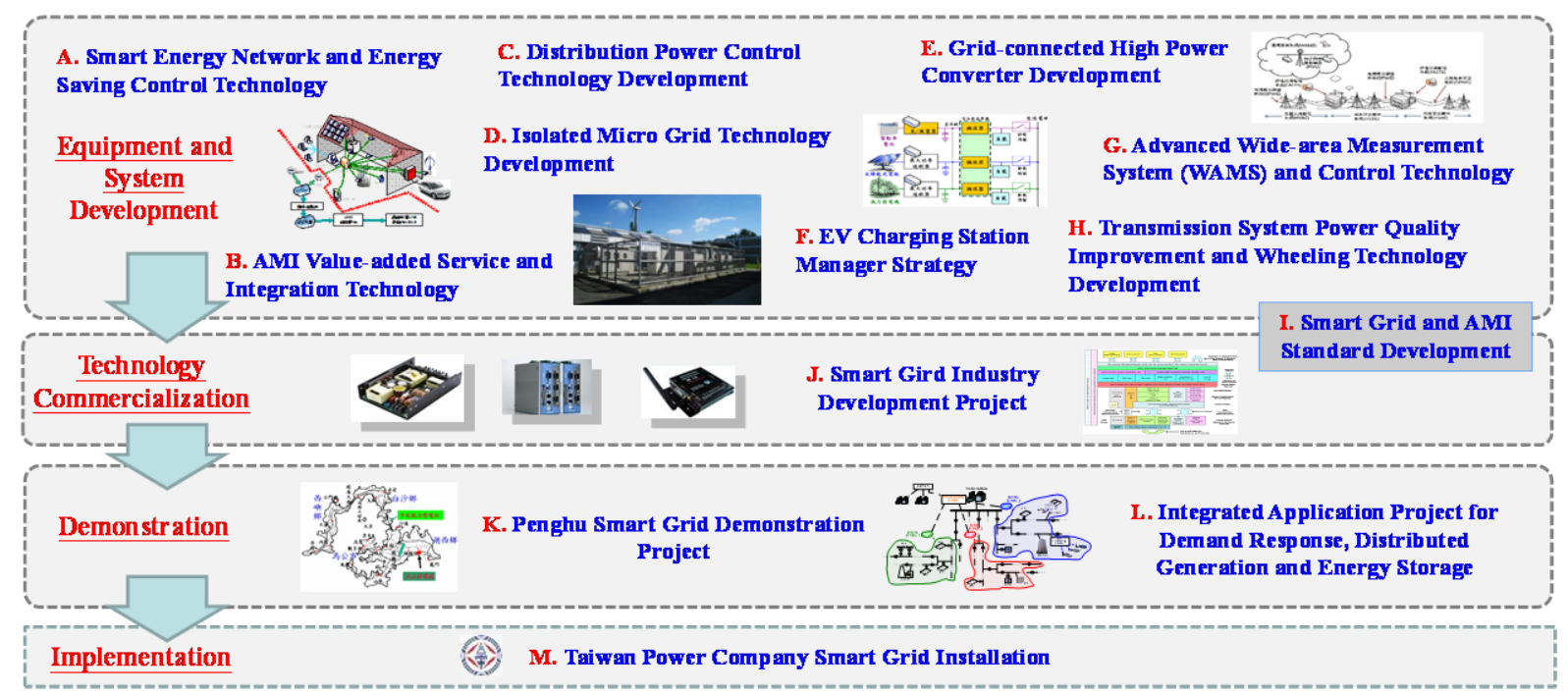

Figure 5. Technology commercialization process of smart grid general project phase 2.

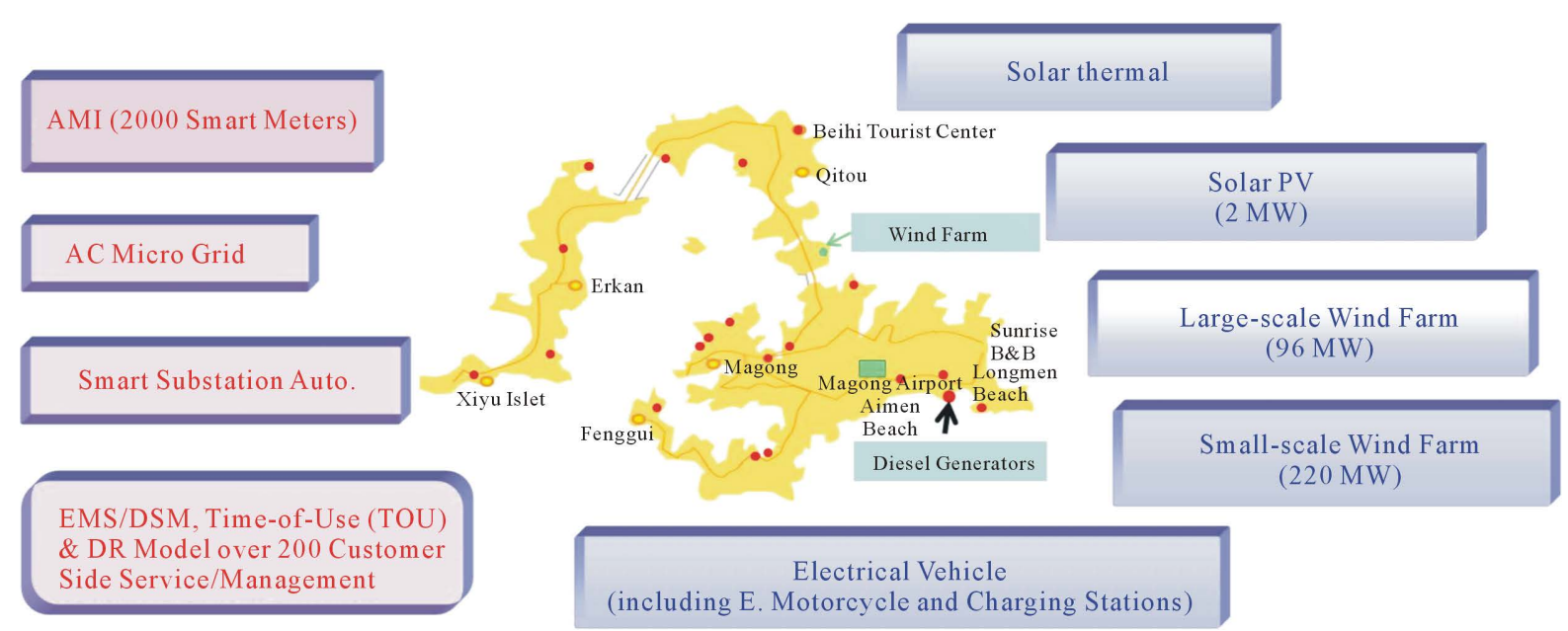

Figure 6. Illustration of Penghu smart grid demonstration site. 
technologies to be used for establishing a grid islanding mechanism. The demonstration site can also take advantage of the distributed generations that Penghu archipelago will install in the future to validate the use of smart grid technology on an MW-grade grid. Penghu Smart Grid Demonstration Project phase 1 will select main island's power supplied areas, substations and transmission lines where demand is more concentrated for an integrated demonstration. An integrated demonstration involving infrastructure and technical testing of smart grid-related technologies from the generation, transmission, distribution and usage aspects will be conducted as shown in Figure 6 [14].

\subsection{Integrated Application Project for Demand Response, Distributed Generation and Energy Storage}

Most of the power bottlenecks in Taiwan are in the north and the demand for power in the north is expected to continue growing. There are various reasons for power bottlenecks around Taiwan. In the north, the excessive loads resulting from residential and small industrial areas. In the center, sheer area makes transmission difficult. In the east, restrictions imposed by terrain results in excessively long lines that are vulnerable to voltage drops. In the south, the excessive number of grid-connected solar power impacts on power supply quality. The analysis of the distribution of renewable energy in Taiwan reveals that solar power is located in the south while wind power is located on the west coast and Penghu archipelago. At the same time, rapid economic and technological development as well as international product competition means that certain industries (e.g. high added value technology industry, science park operators and financial service industries with special requirements) necessitate more rigorous power quality. Taipower will soon launch the low-voltage AMI for use in large demonstration sites with power bottleneck regions to be selected. In terms of amendments to the Electricity Act in Taiwan, the new Electricity Act plans to set up an independent system operator (ISO). Power supplies with better reliability will also need to be provided for regions with transmission/distribution bottlenecks. For power bottleneck regions like Sanchong and Luzhou areas in New Taipei City, if it can be ascertained that power reliability requirements cannot be met, the ISO will then require these regions to provide relatively more reliable power supplies. The VPP concept that combines various DER including renewable energy and energy storage can provide regions with power bottlenecks with a relatively reliable power infrastructure in conjunction with the roll-out of low-voltage AMI, TOU rates and the "Million Solar Roofs Program” which was promoted by the Bureau of Energy, MOEA. As shown in Figure 7, the development of EMS for both the substation and DER are necessary in VPP. Smart Grid General Project Phase 2 will target potential power bottleneck regions in Taiwan and in conjunction with Taipower's roll-out of AMI, then use the "Integrated Application Project for Demand Response, Distributed Generation and Energy Storage” to carry out the planning for VPP demonstration site [15].

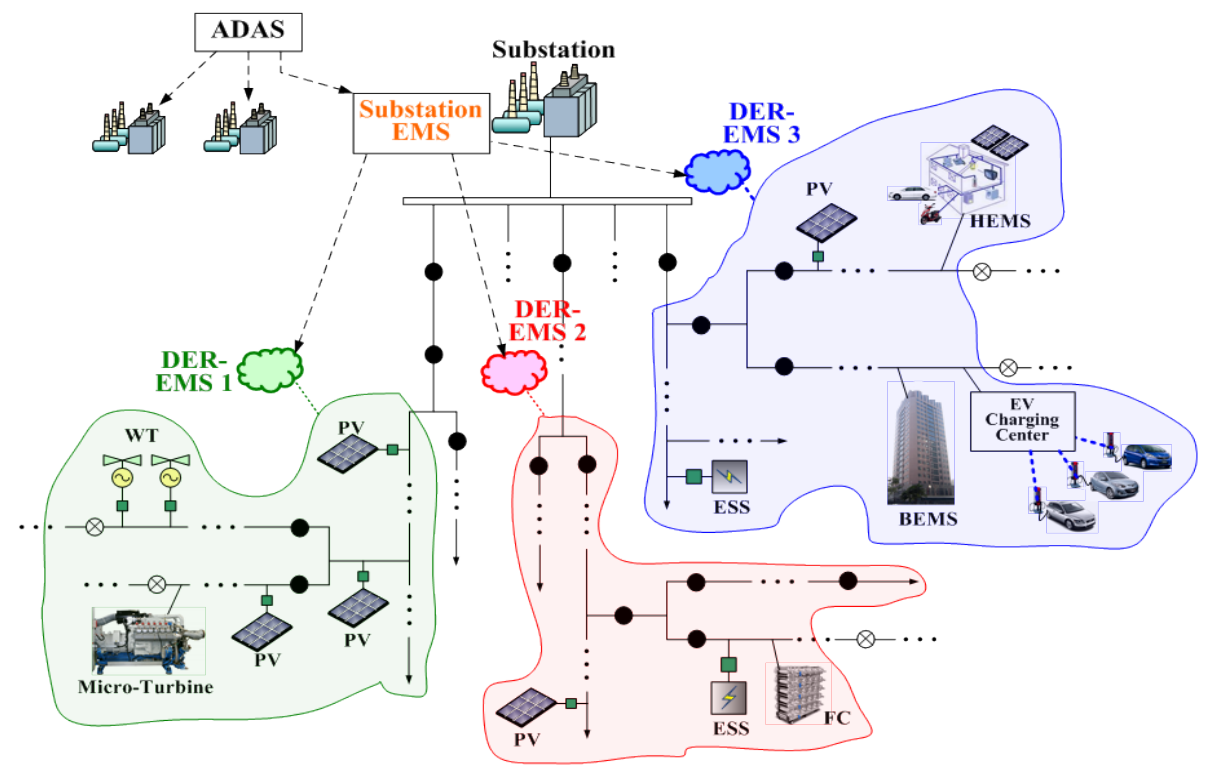

Figure 7. DER-EMS \& substation EMS architecture. 


\section{Summary}

This study has demonstrated the results of NEP-Smart Grid General Project Phase 1 and the planning of Smart Grid General Project Phase 2. This study also demonstrated the importance of the "Penghu Smart Grid Demonstration Project" and the "Integrated Application Project for Demand Response, Distributed Generation and Energy Storage”. In NEP-Smart Grid General Project, we establish a promotion model for smart grid technologies. This promotion model could ensure smart gird technologies which are practically applicable. Furthermore, with the participation of power utility, this model not only changes power utility's perspective, but also enhances its willingness to try and participate in these new technologies. In the foreseeable future, as Taiwan's socialization and industrialization development continue, the electricity's proportion of final energy demand and peak load will also continue to grow. In addition, with other factors such as greenhouse gas emission restrictions and the liberalization of the electric market, Taiwan's power system will have to face more challenges ahead. It is to be expected that the development of smart grid technology led by NEP-Smart Grid General Project will enhance efficiency of power grid and penetration rate of renewable energy, provide better power quality, and also stimulate the power industry to establish a sustainable, stable and capable power system.

\section{Acknowledgements}

The author is grateful to National Energy Program-Project for Promoting and Managing Smart Grid Focus Center, Ministry of Science and Technology for their support about this work.

\section{References}

[1] Chu, C.C., Lin, F.J. and Cheng, P.T. (2012) Smart Grid Development in Taiwan. IEE Japan Journal of Industry Applications, 1, 41-45. http://dx.doi.org/10.1541/ieejjia.1.41

[2] Lin, F.-J. (2010) Planning Proposal of National Science and Technology Program-Intelligent Grid and Advanced Metering Infrastructure General Project. National Science Council.

[3] Duh, T.-J. and Lee, C.-K. (2013) Planning Proposal of National Energy Program, NEP II. Ministry of Science and Technology.

[4] Taiwan Power Company (2013) Taiwan Power Company 2012 Annual Report. Taiwan Power Company, Taiwan.

[5] Taiwan Power Company (2013) Taiwan Power Company Sustainability Report. Taiwan Power Company, Taiwan.

[6] Chen, S.-L., Hsu, S.-C. and Chen, Y. (2007) New Generation Smart Power Grid Management System Feasibility Evaluation Project Final Report. National Applied Research Laboratories, NARLabs.

[7] Bureau of Energy, Ministry of Economic Affairs (2012) Overall Planning of Smart Grid in Taiwan. Bureau of Energy, Ministry of Economic Affairs.

[8] Lin, F.-J., Chen, Y. and Lu, S.-Y. (2012) Smart Grid and Advanced Metering Infrastructure General Project-Overview. NEP I-Smart Grid and Advanced Metering Infrastructure General Project Office.

[9] Lin, F.-J., Tso, C., Chen, Y., Lu, S.-Y. and Hsu, Y. (2013) The Development of Smart Grid Industry and Technology in Taiwan. Taiwan Smart Grid Industry Association.

[10] Taiwan Smart Grid Industry Association (2014) 2013 Industrial Analysis of Smart Grid Technology in Taiwan. Taiwan Smart Grid Industry Association.

[11] Chen, Y., Lu, S.-Y. and Lin, F.-J. (2013) Concept and Operation Mode of Virtual Power Plan. Taiwan Power Electronics Journal, TaiPEA, 11, 46-53.

[12] Lin, F.-J. and Chen, Y. (2013) Planning of National Energy Project Phase 2-Smart Grid General Project. Ministry of Science and Technology.

[13] Executive Yuan (2011) Penghu Low-Carbon Island Project, Executive Yuan.

[14] Chen, C.-S., Liang, P.-F. and Huang, Y.-S. (2014) Integrated Demonstration Project of Penghu Smart Grid. Ministry of Science and Technology, Project Code: MOST103-3113-E-214-002.

[15] Yang, H.-T. (2013) Development of Demand Response, Distributed Energy and Energy Storage System. Ministry of Science and Technology, Project Code: MOST 103-3113-E-006-011. 